\title{
FuZzY OPTIMIZATiOn MODEL FOR WATER Quality Management OF A RIVER SYSTEM
}

\author{
By K. Sasikumar ${ }^{1}$ and P. P. Mujumdar ${ }^{2}$
}

\begin{abstract}
A fuzzy waste-load allocation model, FWLAM, is developed for water quality management of a river system using fuzzy multiple-objective optimization. An important feature of this model is its capability to incorporate the aspirations and conflicting objectives of the pollution control agency and dischargers. The vagueness associated with specifying the water quality criteria and fraction removal levels is modeled in a fuzzy framework. The goals related to the pollution control agency and dischargers are expressed as fuzzy sets. The membership functions of these fuzzy sets are considered to represent the variation of satisfaction levels of the pollution control agency and dischargers in attaining their respective goals. Two formulations - namely, the MAX-MIN and MAX-BIAS formulations - are proposed for FWLAM. The MAX-MIN formulation maximizes the minimum satisfaction level in the system. The MAX-BIAS formulation maximizes a bias measure, giving a solution that favors the dischargers. Maximization of the bias measure attempts to keep the satisfaction levels of the dischargers away from the minimum satisfaction level and that of the pollution control agency close to the minimum satisfaction level. Most of the conventional water quality management models use waste treatment cost curves that are uncertain and nonlinear. Unlike such models, FWLAM avoids the use of cost curves. Further, the model provides the flexibility for the pollution control agency and dischargers to specify their aspirations independently.
\end{abstract}

\section{INTRODUCTION}

A number of water quality management models have been developed in the past for the allocation of assimilativecapacity of a river system. Model results help in setting the amount of waste that can be disposed into the river from various point and nonpoint sources without violating the water quality standards, The intended purpose of these models is to provide economic and technologically feasible solutions acceptable to both the pollution control agency and the dischargers. Water quality management problems have been addressed as multiple objective optimization problems by many researchers (e. $g_{\text {, }}$ Cohon 1978; Loucks et al. 1981; Loucks 1983; Burn and McBean 1985). General methods of solution include the weighting method and the constraint method. Although these methods provide acceptable solutions, they are characterized by the difficulty of assigning unknown relative weights and setting upper bounds in the problem formulation (Loucks 1983). This results in an improper accounting of the aspirations of the various groups such as the pollution control agency and the dischargers.

Water quality management problems are characterized by various types of uncertainties at different stages of the decision-making process to arrive at the optimal allocation of the assimilative capacity of the river system. The type of uncertainty that has received much attention is that due to randomness associated with various components of a water quality system. Two major components considered for randomness are river flow and effluent flow (Lohani and Thanh 1978, 1979; Bum and McBean 1985, 1986; Fugiwara et al. 1986, 1987, 1988; Ellis 1987; Cardwell and Ellis 1993). Another type of uncertainty prominent in the management of water quality systems is the uncertainty due to vagueness associated with describing the goals related to water quality and pollutant abatement. Desirable and permissible water quality criteria, and

\footnotetext{
'Res. Student, Dept. of Civ. Engrg., Indian Inst. of Sci., Bangalore 560 012, India.

${ }^{2}$ Asst. Prof.,Dept. of Civ. Engrg.. Indian Inst. of Sci., Bangalore, India.

Note. Discussion open until September 1, 1998. To extend the closing date one month, a written request must be filed with the ASCE Manager of Journals. The manuscript for this paper was submitted for review and possible publication on November 25,1996 . This paper is part of the Journal of Water Resources Planning and Management, Vol. 124. No. 2, March/April, 1998. QASCE, ISSN 0733-9496/98/0002-0079-0088/ $\$ 4.00+\$ .50$ per page. Paper No. 15548 .
}

minimal pollutant treatment levels, are set up depending on the environmental objectives. In a majority of the cases, establishing these limits is not precise but rather contains an element of vagueness. Thus, the multiple objectives in a water quality system are not only conflicting but are also vague to some extent. The relevant question is not how to eliminate the vagueness but how to cope with it. Multiple and conflicting objectives that are vague can be mathematically quantified and incorporated into the management models using the principles of fuzzy decision-making.

Generally, a water quality management model falls into one of two broad categories: (1) models that minimize the waste treatment cost subject to the constraint that water quality standards are not violated at selected water quality checkpoints in the river system; and (2) models that maximize the water quality subject to a constraint on the waste treatment cost. In a majority of the waste load allocation models, the measure of performance is related to the overall cost of pollution control, including the waste treatment cost. Thus, the waste treatment cost curves play a major role in the model formulation. Generally, the waste treatment cost is not a linear function of the treatment level (Thomann 1972). The difficulty associated with the incorporation of nonlinear cost functions in the management models has been partly overcome in some earlier works by considering the piecewise linear relationship between the treatment level and the cost of treatment. The initial nonconvex portion of such a piecewise linear curve poses nonconvexity problems in optimization (Burn and McBean 1985). Only the convex portion of the piecewise linear cost curve is considered in the optimization by setting the minimum treatment level at a sufficiently high value so that the initial nonconvex portion of the curve is excluded. Another major difficulty associated with the treatment cost curves is that they are not known with certainty. This may lead to only near-optimal solutions in a real case in spite of the sophistication of the model.

The fuzzy waste load allocation model, FWLAM, proposed in this work provides a new paradigm for water quality management of a river system. The model uses the concepts of fuzzy set theory (Zadeh 1965), fuzzy decision-making (Bellman and Zadeh 1970), fuzzy mathematical programming (Zimmermann 1978, 1985), and fuzzy resource allocation (Kindler 1992). The following features of the model make it relevant for practical applications: (1) inclusion of the conflicting objectives of the pollution control agency and dischargers 
in the system; (2) quantification of the vagueness associated with setting up the water quality criteria and minimal pollutant levels; (3) elimination of the treatment cost curves in the model formulation; (4) flexibility for the pollution control agency and dischargers to specify their aspirations independently, thus avoiding the difficulty of assigning unknown relative weights required in the solution of a multiobjective optimization problem using the weighting method; and (5) a basis for more realistic cooperation between the pollution control agency and the dischargers, and cooperation among the dischargers themselves. FWLAM suggests a paradigm for management of water quality systems where emphasis is on rationalization of the waste load allocation process and on efficient use of the limited assimilative capacity of the river system, especially when the number of users in the system will increase in the future. The details of FWLAM are given in the following section.

\section{FUZZY WASTE LOAD ALLOCATION MODEL}

Water quality management for a river network is viewed as a multiple objective optimization problem with conflicting goals of those who are responsible for maintaining the water quality of the river system (e.g,, pollution control agencies) and those who make use of the assimilative capacity of the river system by discharging waste to the water body (e.g., industries). The aspiration of the pollution control agency is to ensure that the pollution is within an acceptable limit by imposing certain water quality and effluent standards. On the other hand, the dischargers prefer to use the assimilative capacity of the river system to minimize the waste treatment cost. The fuzzy waste load allocation model, FWLAM, takes into account these conflicting objectives. A summary of the fuzzy waste load allocation model is given in Fig. 1. Two formulations of the model, the MAX-MIN and MAX-BIAS formulations, are developed using fuzzy multiple objective optimization. Some basic concepts of fuzzy sets and fuzzy multiple objective optimization are briefly introduced in the following subsections as the prerequisites for the development of FWLAM.

\section{Fuzzy Setsand Relevant Basic Operation}

Fuzzy set theory was first introduced by Zadeh (1965) in his seminal paper on fuzzy sets. Detailed study on fuzzy sets can be found in the works of Kaufmann (1975), Dubois and Prade (1980), Klir and Folger (1988), and Klir and Yuan (1995). The concept of a fuzzy set is described as follows. Let $U$ be the universal set with its elements denoted by $\mathbf{x}$. Membership of the element $x$ to a classical subset $G$ (also known as crisp set $\mathrm{G}$ ) of $U$ is defined by the following characteristic function:

$$
\mu_{G}(x)= \begin{cases}1 & \text { if } x \in G \\ 0 & \text { otherwise }\end{cases}
$$

When the valuation set $\{0,1)$ is replaced by the closed set $[0$, 1], a fuzzy set A is defined. The fuzzy set A is characterized by all points denoted by

$$
A=\left\{\left[x, \mu_{A}(x)\right]: x \in U, 0 \leq \mu_{A}(x) \leq 1\right\}
$$

Here, $\boldsymbol{\mu}_{A}(\boldsymbol{x})$ is called the membership function of the fuzzy set $A$ and is a measure of compatibility of the element $x$ with the concept described by the fuzzy set A. Similar to the crisp sets, the basic operations of union, intersection, and complementation are defined for fuzzy sets also. The fuzzy intersection operation that is relevant to fuzzy multiple objective optimization is defined as follows. Let A and B represent two fuzzy sets with the corresponding membership function $\mu_{A}(x)$ and $\mu_{B}(x)$. The fuzzy intersection is defined as

$$
\mu_{A \cap B}(x)=\min \left[\mu_{A}(x), \mu_{B}(x)\right]
$$

Intersection of more than two fuzzy sets $A_{k}, k=1,2, \ldots, n_{A}$ can be obtained by extending this concept. Thus,

$$
\mu_{\left[\cap_{k=1}^{n} A_{k}\right]}(x)=\min _{k}\left[\mu_{A_{k}}(x)\right]
$$

\section{Fuzzy Decision}

The concept of fuzzy decision was first introduced by Beltman and Zadeh (1970). The imprecisely defined goals and constraints are represented as fuzzy sets in the space of alternatives. The confluence of fuzzy goals and fuzzy constraints is defined as the fuzzy decision. The fuzzy decision, $\boldsymbol{Z}$, is defined as the fuzzy set resulting from the intersection of a fuzzy goal, $F$, and a fuzzy constraint, C. Fig. 2 shows the concept of a fuzzy decision. Mathematically,

$$
Z=F \cap C
$$

The membership function of the fuzzy decision $\mathbf{Z}$ is given by

$$
\mu_{Z}(x)=\min \left[\mu_{F}(x), \mu_{C}(x)\right]
$$

The solution $x^{*}$ corresponding to the maximum value of the membership function of the resulting decision $\mathcal{Z}$ is the optimum solution. That is,

$$
\mu_{Z}\left(x^{*}\right)=\lambda^{*}=\max _{x \in Z}\left[\mu_{Z}(x)\right]
$$

Goals and constraints are treated identically in fuzzy multiple objective optimization. Representing the fuzzy goals and fuzzy constraints by fuzzy sets $F_{y}, \mathrm{y}=1,2, \ldots, n_{F}$ the resulting decision can be defined as

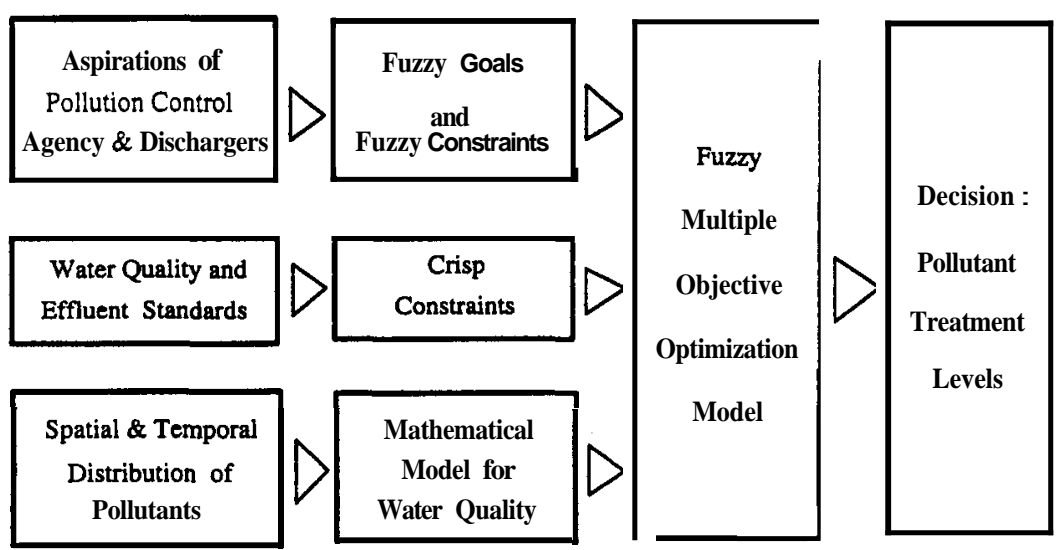

FIG. 1. Fuzzy Waste Load Allocation Model 


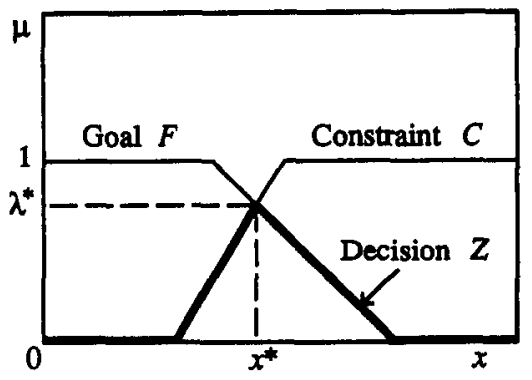

FIG. 2. Fuzzy Decision

$$
Z=\bigcap_{y=1}^{n_{F}} F_{y}
$$

In terms of the corresponding membership functions, the resulting decision for the multiple objective problem is

$$
\mu_{Z}(X)=\min _{Y}\left[\mu_{F_{y}}(X)\right]
$$

where $\boldsymbol{X}$ is the space of alternatives. The optimal solution $X^{*}$ is given by

$$
\mu_{Z}\left(X^{*}\right)=\lambda^{*}=\max _{X E Z}\left[\mu_{Z}(X)\right]
$$

Usually the space of alternatives $\boldsymbol{X}$ (i.e, the decision space) is restricted by precisely defined constraints known as crisp constraints (e,g, mass balance of flows at a junction in a river network for a water allocation problem; minimum waste treatment level imposed on the dischargers by the pollution control agency for a waste load allocation problem). Incorporating these crisp constraints, $g_{h}(X) \leq 0, h=1,2, \ldots, n_{G}$, the crisp equivalent of the fuzzy multiple objective optimization problem can be stated as follows (Zimmermann 1978, 1985; Feng 1983; Kindler 1992; Rao 1993; Sakawa 1995) :

$\max \mathrm{A}$

$$
\begin{gathered}
\text { subject to } \mu_{f_{y}}(X) \geq \lambda \quad \mathrm{Vy} \\
\boldsymbol{g}_{h}(X)=0 \quad \forall h \\
0 \leq \lambda \leq 1
\end{gathered}
$$

\section{Description of the River System}

Table 1 gives the description of a river system to which FWLAM can be applied for water quality management. The relevant components of the system are identified as sets. Set $Q$ represents the collection of meshpoints (water quality checkpoints) where the water quality is of interest in the river system. Set D is the collection of dischargers (e.g, industries). Set $\boldsymbol{T}$ is the collection of uncontrollable sources of pollutants in the system (e.g, BOD addition due to runoff and scour in a stream). Set $\mathrm{P}$ is the collection of the pollutants in the system $(e, g$, point-sources of BOD, a mixture of toxic substances, etc.). Set V is the collection of water quality parameters with a desirable level greater than the permissible level (e.g., dissolved oxygen concentration). Set $S$ is the collection of water quality parameters with a desirable level less than the permissible level (e.g., toxic pollutant concentration). The elements in the sets $\mathrm{V}$ and $S$ are denoted, respectively, by $i$ and $\mathbf{j}$. A pollutant is assumed to affect one or more than one water quality parameter in the sets $\mathrm{V}$ or $\mathrm{S}$ or both. Note that no water quality parameter is common to sets $\mathrm{V}$ and $\mathrm{S}$. Concentration levels of the water quality parameters $i$ and $\mathbf{j}$ at the meshpoint 1 are denoted $C_{l l}$ and $C_{j l}$, respectively. The pollution control agency sets a desirable level, $C_{i l}^{D}$, and a minimum permissible level, $C_{i,}^{L}$, for the water quality parameter $i$ at the meshpoint I $\left(C_{\|}^{D}>C_{i l}^{L}\right)$. Similarly, $C_{j l}^{D}$ and $C_{j l}^{H}$ represent, respectively, the
TABLE 1. Description of River System

\begin{tabular}{l|l|c|c}
\hline \hline & \multicolumn{1}{|c|}{$\begin{array}{c}\text { Description of set } \\
(2)\end{array}$} & $\begin{array}{c}\text { Element } \\
\text { represen- } \\
\text { tation } \\
(3)\end{array}$ & $\begin{array}{c}\text { Number of } \\
\text { elements } \\
(4)\end{array}$ \\
\hline $\mathcal{D}$ & \multicolumn{1}{|c|}{ Water quality meshpoints } & $l$ & $N_{q}$ \\
$P$ & Dischargers & $m$ & $N_{d}$ \\
$T$ & Pollutants & $n$ & $N_{p}$ \\
$V$ & Water quality parameters: desirable & $P$ & $N_{t}$ \\
$S$ & level > permissible level & $i$ & $N_{v}$ \\
& Water quality parameters: desirable & $j$ & $N_{s}$ \\
\hline \hline
\end{tabular}

desirable and maximum permissible levels of the water quality parameter $j$ at the meshpoint $1\left(C_{j l}^{D}<C_{j l}^{H}\right)$. The goals of the pollution control agency and the dischargers are transformed to fuzzy goals in the next subsection using fuzzy sets. These fuzzy goals are then used in formulating the fuzzy decision for the water quality management problem.

\section{Fuuy Goals for Water Quality Management}

Different goals associated with the water quality management of a river system are considered in this section. The quantities of interest are the concentration levels, $C_{n}$ and $C_{m}$, of the water quality parameters, and the fraction removal levels (treatment levels), $x_{i m n}$ and $x_{j m n}$, of the pollutants. The quantities $x_{i m n}$ and $x_{j m n}$ are the fractional removal levels of the pollutant $n$ from the discharger $m$ to control the water quality parameters $i$ and $\mathbf{j}$, respectively. The aspiration level of the discharger $m$ with respect to $x_{w m n}$ ( $\boldsymbol{w}$ stands for either $i$ or $\mathbf{j}$ ) is represented as $x_{x m m}^{L}$. The corresponding maximum fraction removal level acceptable to the discharger $\boldsymbol{m}$ is represented as $x_{w m n}^{M d}$.

The goals of the pollution control agency are:

- Goal $E_{l l}$ : Make the concentration level, $C_{i l}$, of water quality parameter $i$ at the meshpoint $l$ as close as possible to the desirable level, $C_{i 1}^{D}$, so that the water quality at the meshpoint $l$ is enhanced with respect to water quality parameter $i$, for all $i$ and $l$.

- Goal $E_{j \mid}$ : Similar to the goal $E_{i l}$ but with respect to water quality parameter $j$.

The goals of the dischargers are:

- Goal $F_{t m n}$ : Make the fraction removal level $x_{i m n}$ as close as possible to the aspiration level $x_{\text {imn }}^{L}$ for all $i, \mathrm{~m}$, and $n$.

- Goal $F_{j m n}$ : Similar to the goal $F_{i m n}$ but with respect to water quality parameter $j$.

Each of these four goals can be viewed as an imprecisely defined goal. These goals are represented as fuzzy sets. The arguments of the membership functions of the fuzzy sets $E_{i}$ and $E_{\mu}$ are $C_{k}$ and $C_{\mu}$, respectively. Similarly, the arguments of the membership functions of the fuzzy sets $F_{i m n}$ and $F_{j m n}$ are $x_{i m n}$ and $x_{j m n}$, respectively. The fuzzy set corresponding to the decision $\mathrm{Z}$ is then given as

$Z=\left(\bigcap_{t . l} E_{i t}\right) \cap\left(\bigcap_{j . l} E_{j l}\right) \cap\left(\bigcap_{i, m, n} F_{i m n}\right) \cap\left(\bigcap_{j, m, n} F_{j m n}\right)$

The membership function corresponding to the decision $Z$ is given by

$\mu_{\mathrm{Z}}(X)=\underset{i, j, m, n}{\operatorname{minimum}}\left[\mu_{E_{i}}\left(C_{i l}\right), \mu_{E_{j l}}\left(C_{j l}\right), \mu_{F_{i m n}}\left(x_{i m n}\right), \mu_{F_{j m n}}\left(x_{j m n}\right)\right]$ 
where $\mathrm{X}$ is the space of alternatives composed of $C_{i l}, C_{j l}, x_{i m n}$, $x_{j m n}$. The corresponding optimal decision, $\mathrm{X}^{*}$, is given by

$$
\mu_{Z}\left(X^{*}\right)=\lambda^{*}=\max _{X \in Z}\left[\mu_{\mathbf{Z}}(X)\right]
$$

Nonincreasing or nondecreasing membership functions are assigned to each of the fuzzy sets. The nonincreasing membership functions reflect the premise "the less the better or at least not the worse," whereas the nondecreasing membership functions reflect the premise "the more the better or at least not the worse." In other words, the nonincreasing or nondecreasing membership functions represent the aspirations of the pollution control agency and dischargers quantitatively. For example, the dischargers' premise "the less fraction removal level of the waste, the better (in terms of waste treatment cost)" may be expressed using a nonincreasing membership function of the fraction removal level. The membership functions can be either linear or nonlinear. The linear membership functions facilitate solving the fuzzy multiple objective optimization problem using linear programming (Zimmermann 1978, 1985; Feng 1983; Kindler 1992; Rao 1993; Sakawa 1995). The details of the membership functions used in the present study are discussed in the following subsection. The exponents, $\alpha_{(.)}$and $\beta_{(\ldots)}$, appearing in the membership functions are nonzero positive real numbers. The assignment of numerical values to these exponents is subject to the desired shape of the membership functions and the appropriate values may be chosen by the decision-maker. Assignment of a value of 1 to these exponents gives rise to linear membership functions.

\section{Membership Functions for Fuzzy Goals}

Goal $E_{i l}$ : The membership function form for the fuzzy goal $E_{i l}$ is shown in Fig. 3. The desirable level, $C_{i l}^{D}$, for the water quality parameter $i$ at meshpoint $l$ is assigned a membership value of 1 . The minimum permissible level, $C_{i l}^{L}$, is assigned a membership value of zero. The membership function for the fuzzy goal $E_{i l}$ is expressed as

$$
\mu_{E_{i l}}\left(C_{i i}\right)= \begin{cases}0 & C_{i l} \leq C_{i l}^{L} \\ {\left[\frac{C_{i l}-C_{i i}^{L}}{C_{i l}^{D}-C_{i l}^{L}}\right]^{\alpha_{i l}}} & C_{i l}^{L} \leq C_{i l} \leq C_{i l}^{D} \\ 1 & C_{i l} \geq C_{i l}^{D}\end{cases}
$$

This membership function may be interpreted as the variation of satisfaction level of the pollution control agency. The satisfaction of the pollution control agency increases as the concentration level, $C_{i l}$, of the water quality parameter $i$ at the meshpoint $l$ approaches the desirable limit, $C_{i l}^{D}$, starting from the minimum permissible limit, $C_{i t}^{L}$.

Goal $E_{j l}$ : The membership function form of the fuzzy goal $E_{j l}$ is shown in Fig. 4. The desirable level, $C_{j l}^{D}$, for the water quality parameter $j$ at the meshpoint $l$ is assigned a membership value of 1 . The maximum permissible level, $C_{j l}^{H}$ is assigned a membership value of 0 . The membership function for the fuzzy goal $\mathrm{E}_{\circledast}$ is expressed as

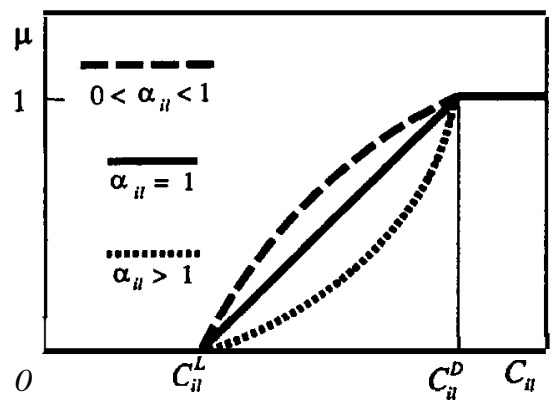

FIG. 3. Membership Functionfor Goal $E_{u}$

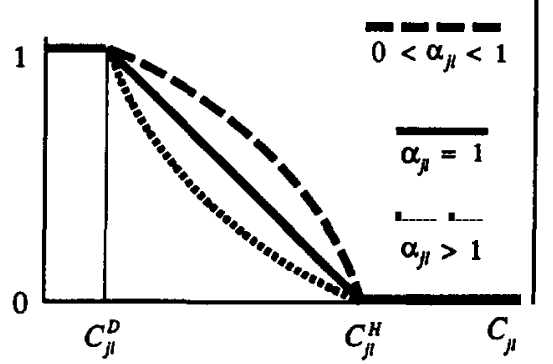

FIG. 4. MembershipFunctionfor Goal $E_{\mu \prime}$

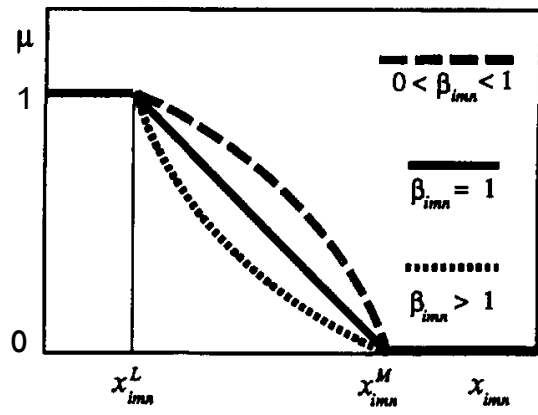

FIG. 5. MembershipFunctionfor Goal $\boldsymbol{F}_{\mathrm{lmn}}$

$$
\mu_{E_{j l}}\left(C_{j l}\right)= \begin{cases}1 & C_{j l} \leq C_{j l}^{D} \\ {\left[\frac{C_{j l}^{H}-C_{j l}}{C_{j l}^{H}-C_{j l}^{D}}\right]^{\alpha_{j l}}} & C_{j l}^{D} \leq C_{j l} \leq C_{j l}^{H} \\ 0 & C_{j l}=C_{j l}^{H}\end{cases}
$$

Similar to the membership function for the fuzzy goal $E_{i l}$, the membership function for the fuzzy goal $E_{j}$ may also be interpreted as the variation of the satisfaction level of the pollution control agency with the concentration level, $C_{j}$, of water quality parameter $j$.

Goal $F_{i m n}$ : The membership function form for the fuzzy goal $F_{i m n}$ is shown in Fig. 5. The fraction removal level, $x_{i m n}^{L}$, corresponding to the aspiration level of the discharger $\boldsymbol{m}$ with regard to $x_{i m n}$ is assigned a membership value of 1 . The maximum acceptable level, $x_{i m n}^{M}$, is assigned a membership value of 0 . The membership function for the fuzzy goal $F_{\text {Imn }}$ is expressed as

$$
\mu_{F_{i m n}}\left(x_{i m n}\right)= \begin{cases}1 & \mathrm{x} \leq x_{i m n}^{L} \\ {\left[\frac{x_{i m n}^{M}-x_{i m n}}{x_{i m n}^{M}-x_{i m n}^{L}}\right]^{\beta_{i m n}}} & x_{i m n}^{L} \leq x_{i m n} \leq x_{i m n}^{M} \\ 0 & x_{i m n} \geq x_{i m n}^{M}\end{cases}
$$

This membership function may be interpreted as the variation of satisfaction level of the discharger $\boldsymbol{m}$ in treating the pollutant $n$ to control the water quality parameter $i$ in the river system.

Goal $F_{j m n}$ : The membership function form for the fuzzy goal $F_{j m n}$ is similar to that of the fuzzy goal $F_{i m n}$, but the index $i$ replaced by the index $j$. The membership function for the fuzzy goal $F_{\min }$ can be expressed as

$$
\mu_{F_{j m n}}\left(x_{j m n}\right)= \begin{cases}1 & x_{j m n} \leq x_{j m n}^{L} \\ {\left[\frac{x_{j m n}^{M}-x_{j m n}}{x_{j m n}^{M}-x_{j m n}^{L}}\right]^{\beta_{j m n}}} & x_{j m n}^{L} \leq x_{j m n} \leq x_{j m n}^{M} \\ 0 & x_{j m n} \geq x_{j m n}^{M}\end{cases}
$$

Similar to the fuzzy goal $F_{i m n}$, this membership function can also be interpreted as the variation of satisfaction level of the 
discharger $m$ in treating the pollutant $\boldsymbol{n}$ to control the water quality parameter $j$, Based on the membership functions for the fuzzy goals, the MAX-MIN and MAX-BIAS formulations of FWLAM are presented in the following subsection.

\section{MAX-MIN Formulation}

The crisp equivalent of the fuzzy multiple objective optimization problem, (11) through (14), provides the basis for the MAX-MIN formulation of FWLAM. The model maximizes the satisfaction level, A, in the system. The model is expressed as

$\max A$

subject to

$$
\begin{gathered}
\mu_{E_{i l}}\left(C_{i l}\right) \geq \lambda \quad \forall i, l \\
\mu_{E_{j l}}\left(C_{j l}\right) \geq \lambda \quad \forall j, l \\
\mu_{F_{i m n}}\left(x_{i m n}\right) \geq \lambda \quad \forall i, m, n \\
\mu_{F_{j m n}}\left(x_{j m n}\right) \geq \lambda \quad \forall j, m, n \\
C_{u}^{L} \leq C_{i l} \leq C_{i l}^{D} \quad \forall i, l \\
C_{j}^{D} \leq C_{j l} \leq C_{j}^{H} \quad \forall j, l \\
x_{i m n}^{L} \leq x_{i m n} \leq x_{i m n}^{M} \quad \forall i, m, n \\
x_{j m n}^{L} \leq x_{j m n} \leq x_{j m n}^{M} \quad \forall j, m, n \\
x_{i m n}^{\mathrm{MNN}} \leq x_{i m n} \leq x_{i m n}^{\mathrm{MAX}} \quad \forall i, m, n \\
x_{j m n}^{\mathrm{MNN}} \leq x_{j m n} \leq x_{j m n}^{\mathrm{MAX}} \quad \forall j, m, n \\
0 \leq \lambda \leq 1
\end{gathered}
$$

The crisp constraints (27) through (33) determine the space of alternatives. The constraints (27) and (28) are based on the water quality requirements set by the pollution control agency through the desirable and permissible limits of the water quality parameters $i$ and $j$, respectively. The aspiration level and maximum acceptable level of pollutant treatment efficiencies set by the dischargers are expressed in constraints (29) and (30). However, the pollution control agency imposes minimal treatment levels that are expressed as the lower bounds, $x_{i m n}^{\mathrm{MIN}}$ and $x_{j m n}^{\mathrm{MIN}}$, in constraints (31) and (32). The upper bounds, $x_{i m n}^{\mathrm{MAX}}$ and $x_{m n}^{\mathrm{MAX}}$, in these constraints represent the technologically possible maximum fraction removal levels. Because the maximum acceptable level of pollutant treatment cannot exceed the technologically possible upper limit, the constraints (29) and (31), and (30) and (32) can be simplified as follows:

$$
\begin{aligned}
& \max \left[x_{i m n}^{L}, x_{i m n}^{\mathrm{Men}}\right] \leq x_{i m n} \leq x_{i m n}^{M} \quad \forall i, m, n \\
& \max \left[x_{j m n}^{L}, x_{j m n}^{\mathrm{MIN}} \mathrm{I} \leq x_{j m n} \leq x_{j m n}^{M} \quad \forall j, m, n\right.
\end{aligned}
$$

Constraint (33) represents the bounds on the parameter A. It may be noted that the constraints (23) through (26) define the parameter A as the minimum satisfaction level in the system. The objective is to find $X^{*}$ corresponding to the maximum value $\lambda^{*}$ of the parameter $A$. The optimum value $\lambda^{*}$ corresponds to the maximized minimum (max-min) satisfaction level in the system. The solution $X^{*}$ is referred to as the best compromise solution to the multiple objective optimization problem (Kindler 1992). Substituting the expressions for the membership functions from (18) through (21) into constraints (23) through (26), respectively, yields the MAX-MIN formulation, given as

$\operatorname{rnax} \boldsymbol{\lambda}$

$$
\begin{gathered}
{\left[\frac{C_{l l}-C_{l l}^{L}}{C_{i l}^{D}-C_{i l}^{L}}\right]^{\alpha_{l l}} \geq \lambda \quad \forall i, l} \\
{\left[\frac{C_{j l}^{H}-C_{j l}}{C_{j l}^{H}-C_{j l}^{D}}\right]^{\alpha_{j \prime}} \geq \lambda \quad \forall j, l} \\
{\left[\frac{x_{i m n}^{M}-x_{i m n}}{x_{i m n}^{M}-x_{i m n}^{L}}\right]^{\beta_{m n n}} \geq \lambda \quad \forall i, m, n} \\
{\left[\frac{x_{j m n}^{M}-x_{j m n}}{x_{j m n}^{M}-x_{j m n}^{L}}\right]^{\beta_{j m n}} \geq \lambda \quad \forall j, m, n}
\end{gathered}
$$

and to constraints (27), (28), (33), (34), and (35).

The concentration level, $C_{w l}$, of the water quality parameter $\mathrm{w}$ (the index w stands for either $i$ orj ) at the meshpoint 1 can be related to the fraction removal level, $x_{w m n}$, of the pollutant $\boldsymbol{n}$ from the discharger $m$ to control the water quality parameter $w$. Table 1 shows that the dischargers in the set $\mathrm{D}$ and the uncontrollable sources in the set $\mathbf{T}$ may affect the water quality parameter $\mathrm{w}$ at the meshpoint 1 . This can be mathematically expressed as

$$
C_{w l}=\sum_{m=1}^{N_{d}} \sum_{n=1}^{N_{p}} f_{w l m n}\left(L_{w l m n}, x_{w m n}\right)+\sum_{p=1}^{N_{t}} \sum_{n=1}^{N_{p}} f_{w l p n}\left(L_{w l p n}\right)
$$

where $L_{w t m n}$ is the concentration of the pollutant $\boldsymbol{n}$ prior to treatment from the discharger $m$ that affects the water quality parameter $\mathrm{w}$ at the meshpoint $l, L_{\text {wlpn }}$ is the concentration of the pollutant $\boldsymbol{n}$ from the uncontrollable source $\mathrm{p}$ that affects the water quality parameter $\mathrm{w}$ at the meshpoint 1 . The transfer functions $f_{w / m n}(\cdot, \cdot)$ and $f_{w / p n}(\cdot)$ represent the concentration levels of the water quality parameter $\mathrm{w}$ due to $L_{w / m n}\left(1-x_{w / m n}\right)$, and $L_{w / \rho n}$, respectively. These transfer functions can be evaluated using appropriate mathematical models that determine the spatial and temporal distribution of the water quality parameter due to the pollutants in the river system. From a water quality management point of view, it is assumed that the transfer functions can be evaluated using available water quality models. Substitution for $C_{l l}$ and $C_{j l}$ in the constraints (37) and (38) using (41) gives linear or nonlinear constraints in terms of the fraction removal levels. The solution will be $x^{*}$ and $\lambda^{*}$ where $\hat{\mathrm{X}}^{*}$ corresponds to the optimal fraction removal levels. Thus,

$$
\hat{\mathbf{X}} *=\left\{x_{i m n}^{*}, x_{j m n}^{*}\right\}
$$

where $\boldsymbol{x}_{i m n}^{*}$ and $x_{j m n}^{*}$ are the fraction removal levels of the pollutant $n$ from the discharger $m$ to control water quality parameters $i$ and $j$, respectively.

\section{MAX-BIAS Formulation}

The MAX-MIN formulation gives a solution that maximizes the minimum satisfaction level in the system without explicitly considering criteria for minimizing the pollutant treatment cost. Minimization of the total treatment cost is achieved by developing a formulation that is biased to the dischargers. The MAX-BIAS formulation discussed in this section gives a solution that favors the dischargers and thereby indirectly reduces the total treatment cost. Let A be the minimum satisfaction level in the system corresponding to a vector of fraction removal levels $\mathbf{X}$. Consider the deviation of satisfaction levels of the pollution control agency and the dischargers from the minimum satisfaction level A. Represent the deviations as

$$
\begin{array}{cc}
d_{i l}=\mu_{E_{i l}}\left(C_{i i}\right)-\mathrm{A} & \forall i, l \\
d_{j l}=\mu_{E_{j l}}\left(C_{i l}\right)-\lambda & \forall j, l \\
d_{i m n}=\mu_{F_{i m n}}\left(x_{i m n}\right)-\lambda & \forall i, m, n
\end{array}
$$

subject to 


$$
d_{j m n}=\mu_{F_{m n}}\left(x_{j m n}\right)-\lambda \quad \forall j, m, n
$$

Summing the deviations over all $\boldsymbol{i}, \mathbf{j}, 1, \mathbf{m}$, and $\mathrm{n}$ gives

$$
\begin{gathered}
d_{1}=\sum_{i=1}^{N_{v}} \sum_{i=}^{N_{q}} d_{i l}=\sum_{i=1}^{N_{v}} \sum_{i=1}^{N_{q}} \mu_{E_{i l}}\left(C_{i l}\right)-N_{v} N_{q} \lambda \\
d_{2}=\sum_{j=1}^{N_{s}} \sum_{i=1}^{N_{q}} d_{j l}=\sum_{j=1}^{N_{s}} \sum_{i=1}^{N_{q}} \mu_{E_{j l}}\left(C_{j l}\right)-N_{s} N_{q} \lambda \\
d_{3}=\sum_{n=1}^{N_{p}} \sum_{m=1}^{N_{d}} \sum_{i=1}^{N_{s}} d_{i m n}=\sum_{n=1}^{N_{p}} \sum_{m=1}^{N_{d}} \sum_{i=1}^{N_{i q}} \mu_{F_{i m n}}\left(x_{i m n}\right)-N_{p} N_{d} N_{v} \lambda \\
d_{4}=\sum_{n=1}^{N_{p}} \sum_{m=1}^{N_{d}} \sum_{j=1}^{N_{s}} d_{j m n}=\sum_{n=1}^{N_{p}} \sum_{m=1}^{N_{d}} \sum_{j=1}^{N_{s}} \mu_{F_{j m n}}\left(x_{j m n}\right)-N_{p} N_{d} N_{s} \lambda
\end{gathered}
$$

Minimization of the quantities $d_{1}$ and $d_{2}$ and maximization of the quantities $d_{3}$ and $d_{4}$ result in a solution that is biased to the dischargers. It may be noted that minimization of $d_{1}$ and $d_{2}$, and maximization of $d_{3}$ and $d_{4}$ together result in pulling the satisfaction levels of the pollution control agency toward the minimum satisfaction level $\mathbf{A}$, and pushing the satisfaction levels of the dischargers away from the minimum satisfaction level A. Pulling the satisfaction levels of the pollution control agency toward the minimum satisfaction level brings the concentration levels of the water quality parameters close to the permissible levels. This, in turn, permits more use of the assimilative capacity of the river system. This means more waste disposal to the river system and lower fraction removal levels. The ideal solution from a cost minimization point of view may be achieved by keeping the fraction removal levels as low as possible. Similarly, pushing the satisfaction levels of the dischargers away from the minimum satisfaction level $\mathrm{A}$ brings the fraction removal levels as close to the aspiration levels of the dischargers, and this helps to reduce the waste treatment cost. The bias index, $\eta$, is then defined as

$$
\eta=d_{3}+d_{4}-d_{1}-d_{2}
$$

Simplifying (51) using (18) through (21) allows the bias index, $\eta$, to be expressed as

$$
\begin{aligned}
\eta & =-\sum_{i=1}^{N_{q}} \sum_{i=1}^{N_{v}}\left[\frac{C_{i l}-C_{j l}^{L}}{C_{i l}^{D}-C_{i l}^{L}}\right]^{\alpha_{l}}-\sum_{i=1}^{N_{q}} \sum_{j=1}^{N_{s}}\left[\frac{C_{j l}-C_{j l}^{L}}{C_{j l}^{D}-C_{j l}^{L}}\right]^{\alpha_{j l}} \\
& +\sum_{n=1}^{N_{p}} \sum_{m=1}^{N_{d}} \sum_{i=1}^{N_{\nu}}\left[\frac{x_{i m n}^{M}-x_{i m n}}{x_{i m n}^{M}-x_{i m n}^{L}}\right]^{\beta_{l m n}}+\sum_{n=1}^{N_{p}} \sum_{m=1}^{N_{d}} \sum_{j=1}^{N_{s}}\left[\frac{x_{j m n}^{M}-x_{j m n}}{x_{j m n}^{M}-x_{j m n}^{L}}\right]^{\beta_{j m n}} \\
& +\left(N_{v}+N_{s}\right)\left(N_{q}-N_{p} N_{d}\right) \lambda
\end{aligned}
$$

Maximization of this bias index, $\eta$, yields a solution that is biased to the dischargers and reduces the total treatment cost. The MAX-BIAS formulation is then given as

$$
\max \eta
$$

subject to the constraints (27), (28), (33) through (35), and (37) through (40). The applications of the MAX-MIN and MAX-BIAS formulations of FWLAM are discussed in the following section.

\section{MODEL APPLICATION}

The application of FWLAM is demonstrated with a hypothetical river network shown in Fig. 6. The river network is discretized into nine river reaches and each reach receives a point-source of BOD waste load from a discharger located at the beginning of the reach. The only pollutant in the system is the point-source of BOD waste load. The water quality parameter of interest is the dissolved oxygen deficit (DO deficit) at a finite number of meshpoints due to these point-sources of BOD. Water quality is checked at $\mathbf{2 3}$ meshpoints, as shown in Fig. 6. The middle meshpoint in a reach corresponds to half of the travel time of flow between the meshpoints at the beginning and end of the reach. The data pertaining to the river flows and effluent flows are given in Table 2. The value of the dissolved oxygen deficit at a meshpoint can be expressed in terms of the fraction removal levels of BOD associated with various dischargers located upstream of the meshpoint under

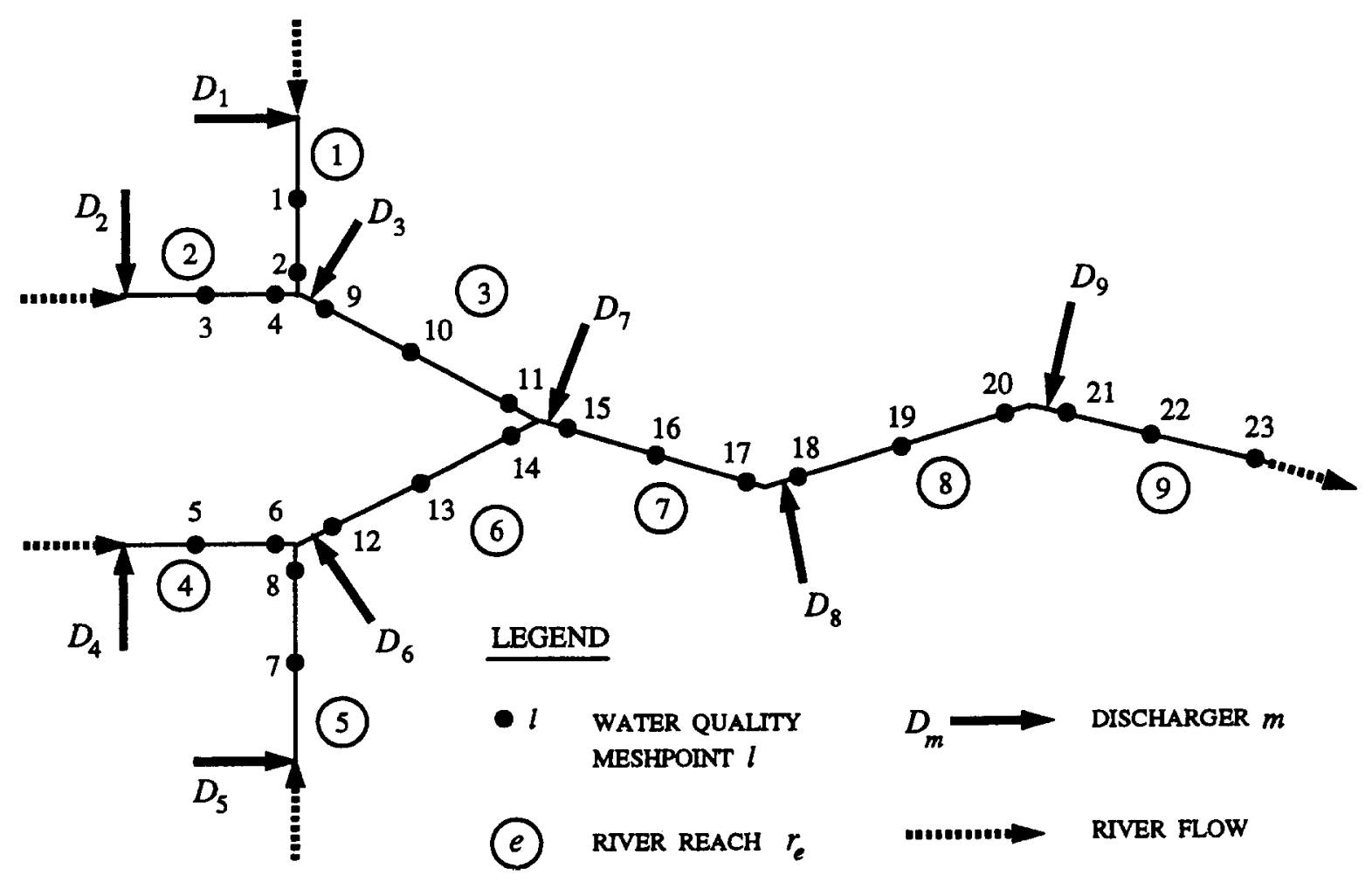

FIG. 6. Hypothetical River Network 


\begin{tabular}{|c|c|c|c|c|c|c|c|c|c|c|c|c|}
\hline \multicolumn{4}{|c|}{ Effluent Flow Data } & \multicolumn{9}{|c|}{ River Flow Data } \\
\hline $\begin{array}{c}\text { Discharger } \\
\text { (1) }\end{array}$ & $\begin{array}{c}\text { Effluent } \\
\text { flow rate } \\
\left(10^{4} \mathrm{~m}^{3} /\right. \\
\text { day }) \\
(2) \\
\end{array}$ & \begin{tabular}{|c|} 
BOD \\
concentration \\
$(\mathrm{mg} / \mathrm{L})$ \\
$(3)$ \\
\end{tabular} & \begin{tabular}{|c|} 
DO \\
concentration \\
$(\mathrm{mg} / \mathrm{L})$ \\
$(4)$ \\
\end{tabular} & $\begin{array}{c}\text { River } \\
\text { reach } \\
r_{-} \\
(5) \\
\end{array}$ & \begin{tabular}{|} 
Flow \\
$\left(10^{6} \mathrm{~m}^{3} /\right.$ \\
day $)$ \\
$(6)$
\end{tabular} & 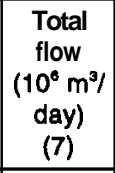 & $\begin{array}{c}\text { Time } \\
\text { of } \\
\text { flow } \\
\text { (day) } \\
(8) \\
\end{array}$ & $\begin{array}{c}\text { Deoxygenation } \\
\text { rate constant } \\
\text { (1/day) } \\
(9) \\
\end{array}$ & $\begin{array}{c}\text { Reaeration } \\
\text { rate } \\
\text { constant } \\
\text { (1/day) } \\
(10) \\
\end{array}$ & \begin{tabular}{|c|} 
Saturation DO \\
concentration \\
$(\mathrm{mg} / \mathrm{L})$ \\
$(11)$
\end{tabular} & $\begin{array}{c}\text { Permissible } \\
\text { DO deficit } \\
\text { (mg/L) } \\
\text { (12) }\end{array}$ & $\begin{array}{c}\text { Desirable } \\
\text { DO } \\
\text { deficit } \\
\text { (mg/L) } \\
\text { (13) }\end{array}$ \\
\hline $\begin{array}{l}D_{1} \\
D_{2} \\
D_{3} \\
D_{4} \\
D_{3} \\
D_{6} \\
D_{7} \\
D_{1} \\
D_{0}\end{array}$ & \begin{tabular}{r|}
2.134 \\
10.738 \\
4.178 \\
6.415 \\
8.319 \\
7.554 \\
9.832 \\
3.511 \\
5.180
\end{tabular} & \begin{tabular}{r|}
1.250 \\
525 \\
1.878 \\
723 \\
1,272 \\
2,080 \\
2.564 \\
1.842 \\
932
\end{tabular} & $\begin{array}{l}1.23 \\
2.15 \\
2.16 \\
1.80 \\
2.40 \\
1.41 \\
1.62 \\
1.70 \\
1.93\end{array}$ & $\begin{array}{l}r_{1} \\
r_{2} \\
r_{3} \\
r_{1} \\
r_{1} \\
r_{6} \\
r_{7} \\
r_{8} \\
r_{9}\end{array}$ & $\begin{array}{r}4.6183 \\
3.2574 \\
7.8757 \\
3.9821 \\
5.2394 \\
9.2215 \\
17.0972 \\
17.0972 \\
17.0972\end{array}$ & \begin{tabular}{|r|}
4.63964 \\
3.36478 \\
8.04620 \\
4.04625 \\
5.32259 \\
9.44438 \\
17.58890 \\
17.62401 \\
17.67581 \\
\end{tabular} & \begin{tabular}{|l|}
0.316 \\
1.312 \\
0.642 \\
1.281 \\
0.732 \\
1.218 \\
1.787 \\
1.823 \\
2.131
\end{tabular} & $\begin{array}{l}0.331 \\
0.328 \\
0.378 \\
0.410 \\
0.320 \\
0.357 \\
0.393 \\
0.383 \\
0.390\end{array}$ & $\begin{array}{l}0.847 \\
0.743 \\
0.532 \\
0.831 \\
0.754 \\
0.670 \\
0.580 \\
0.425 \\
0.210\end{array}$ & $\begin{array}{r}10.10 \\
9.85 \\
9.64 \\
9.78 \\
10.20 \\
9.90 \\
9.85 \\
9.65 \\
9.50\end{array}$ & $\begin{array}{l}3.5 \\
3.0 \\
3.5 \\
3.5 \\
3.0 \\
3.0 \\
4.0 \\
3.5 \\
4.0\end{array}$ & $\begin{array}{l}0.0 \\
0.5 \\
0.0 \\
0.0 \\
0.0 \\
0.5 \\
1.0 \\
1.5 \\
1.5\end{array}$ \\
\hline
\end{tabular}

consideration. The transfer function that expresses the DO deficit at a meshpoint in terms of the concentration of pointsource of BOD and the fraction removal levels can be obtained using the one-dimensional steady-state Streeter-Phelps BODDO equations (Gromiec et al. 1983; Thomann and Mueller 1987; James and Elliot 1993). Different methods that employ the Sweeter-Phelps equations to predict the spatial distribution of DO deficit in a river network with multiple reaches are available in the literature (e,g, Arbabi and Elzinga 1975; Fug. iwara et al. 1986). A suitable adoption of the model proposed by Fugiwara et al. (1986) is used in the present study.

It may be noted that since the desirable level of the DO deficit is smaller than the permissible level, this water quality parameter belongs to the set $\mathrm{S}$ described in Table 1 . The sets $\mathbf{V}$ and $\mathrm{T}$ are empty sets. The elements in the sets $\mathrm{P}, \mathrm{D}$, and $\mathrm{Q}$ are, respectively, BOD point-source, nine dischargers, and $\mathbf{2 3}$ meshpoints. Since the sets $\mathrm{P}$ and $\mathrm{S}$ contain only one element each, the suffixes $j$ and $n$ are dropped from the constraints and objective function for convenience. Denoting the DO deficit at the water quality meshpoint 1 by $C_{l}$, and the fraction removal level for the mth discharger by $x_{m}$, and using linear membership functions for the fuzzy goals (i.e., $\alpha_{(. .)}=\beta_{(. .)}=$ 1), the MAX-MIN and MAX-BIAS formulations can be simplified using the constraints (28), (33), (35), (38), and (40). The MAX-MIN formulation can be simplified as follows:

$\max \mathbf{A}$

subject to

$$
\begin{gathered}
\frac{C_{l}^{H}-C_{l}}{C_{l}^{H}-C_{l}^{D}} \geq \lambda \quad \forall l \\
\frac{x_{m}^{M}-x_{m}}{x_{m}^{M}-x_{m}^{L}} \geq \lambda \quad \forall m \\
C_{l}^{D} \leq C_{l} \leq C_{l}^{H} \quad \forall l \\
\max \left[x_{m}^{L}, x_{m}^{\mathrm{MNN}}\right] \leq x_{m} \leq x_{m}^{M} \quad \forall m \\
0 \leq \lambda \leq 1
\end{gathered}
$$

The MAX-BIAS formulation can be simplified as follows:

$\max \eta=-\sum_{i=1}^{N_{q}(-23)}\left[\frac{C_{l}^{H}-C_{l}}{C_{l}^{H}-C_{l}^{D}}\right]+\sum_{m=1}^{N_{d}(=9)}\left[\frac{x_{m}^{M}-x_{m}}{x_{m}^{M}-x_{m}^{L}}\right]+14 \mathrm{~A}$

subject to constraints (55) through (59). The coefficient 14 of the-parameter $\mathrm{A}$ is obtained as $\left\{\left(N_{v}+N_{s}\right)\left(N_{q}-N_{p} N_{d}\right)=(\mathbf{0}+\right.$ 1) $(23-1 \cdot 9)=141$.

Details of the membership functions for the fuzzy goals are given in Table 3. Two typical membership functions corresponding to the fuzzy goals $E_{3}$ (goal of the pollution control agency related to the DO deficit at meshpoint 3 ), and $\boldsymbol{F}_{\mathbf{9}}$ (goal related to the fraction removal level for discharger 9) are shown in Figs. 7 and 8, respectively. A minimal fraction re-
TABLE 3. Details of Membership Functions

\begin{tabular}{c|c|c|c|c|c}
\hline \hline \multirow{2}{*}{$\begin{array}{c}\text { For all Meshpoints } \\
I \text { in Reach } r_{6}\end{array}$} & \multicolumn{2}{|c|}{ Goal $E_{1}$} & \multicolumn{3}{|c}{ Goal $F_{m}$} \\
\cline { 2 - 6 }$(1)$ & $C_{l}^{H}$ & $C_{l}^{o}$ & & & \\
$(\mathrm{mg} / \mathrm{L})$ & $(\mathrm{mg} / \mathrm{L})$ & Discharger & $x_{m}^{L}$ & $x_{m}^{M}$ \\
$(2)$ & $(3)$ & $(4)$ & $(5)$ & $(6)$ \\
\hline$r_{1}$ & 3.5 & 0.0 & $D_{1}$ & 0.25 & 0.75 \\
$r_{2}$ & 3.0 & 0.5 & $D_{2}$ & 0.35 & 0.80 \\
$r_{3}$ & 3.5 & 0.0 & $D_{3}$ & 0.30 & 0.85 \\
$r_{4}$ & 3.5 & 0.5 & $D_{4}$ & 0.35 & 0.75 \\
$r_{5}$ & 3.0 & 0.0 & $D_{9}$ & 0.35 & 0.80 \\
$r_{6}$ & 3.0 & 0.5 & $D_{6}$ & 0.25 & 0.90 \\
$r_{7}$ & 4.0 & 1.0 & $D_{7}$ & 0.35 & 0.90 \\
$r_{8}$ & 3.5 & 1.5 & $D_{8}$ & 0.35 & 0.85 \\
$r_{9}$ & 4.0 & 1.5 & $D_{9}$ & 0.30 & 0.75 \\
\hline \hline
\end{tabular}

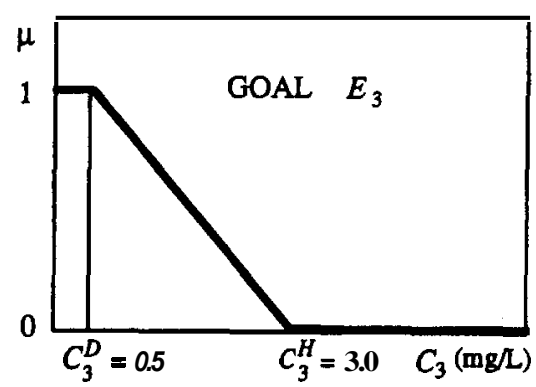

FIG. 7. MembershipFunction for Goal $E_{3}$

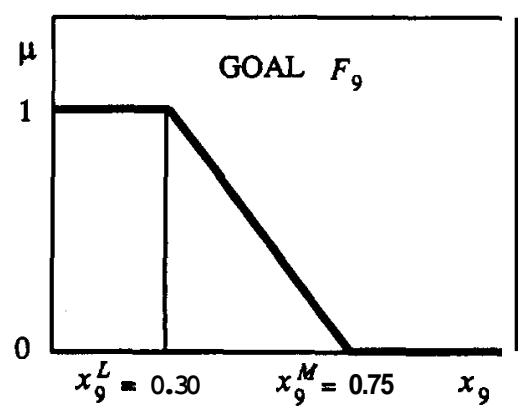

FIG. 8. MembershipFunctionfor Goal $\boldsymbol{F}_{0}$

moval level of $\mathbf{0 . 3 0}$ is imposed by the pollution control agency on all the dischargers (i.e., $x_{m}^{\mathrm{MN}}=\mathbf{0 . 3} \mathbf{V m}$ ). As pointed out previously, the DO deficit, $C_{l}$ at meshpoint 1 can be expressed as a function of fraction removal levels $x_{k}$, where $k$ corresponds to the dischargers upstream of the meshpoint 1. Use of Streeter-Phelps equations results in linear transfer functions for $C_{1}$. This facilitates the use of linear programming technique to solve both the MAX-MIN and MAX-BIAS formulations. The results obtained by applying the two formulations to the river system are described in the following paragraphs. 


\section{RESULTS AND DISCUSSION}

The results of the analysis are summarized in Table 4 and Figs 9 and 10. Table 4 gives the optimum fraction removal levels and minimum DO concentration in each river reach corresponding to the MAX-MIN and MAX-BIAS formulations. Also shown in Table $\mathbf{4}$ are the desirable and minimum permissible DO concentrations. These values correspond to the desirable and maximum permissible DO deficits in each river reach that are given in Table 2. The bar charts shown in Figs 9 and 10 compare the fraction removal levels and the minimum DO concentration in the reaches, respectively, for the MAX-MIN and MAX-BIAS formulations. The MAX-MIN formulation results in higher fraction removal levels (except for the dischargers 6 and 7). This results in higher BOD removal and, as a consequence, a higher DO concentration levels in the river system. As shown in Fig. 10, the minimum DO concentration is well above the minimum permissible DO concentration in all the reaches for MAX-MIN formulation. Therefore, it may be concluded that the MAX-MIN formulation enhances the water quality in the system and favors the

TABLE 4. Results of MAX-MIN (MM) and MAX-BIAS (MB) Formulations

\begin{tabular}{|c|c|c|c|c|c|c|c|}
\hline \multirow[b]{2}{*}{$\begin{array}{l}\text { Discharger } \\
\text { (1) }\end{array}$} & \multicolumn{2}{|c|}{$\begin{array}{c}\text { Fraction } \\
\text { Removal } \\
\text { Level }\end{array}$} & \multirow{2}{*}{$\begin{array}{c}\text { River } \\
\text { Reach, } \\
r_{0} \\
(4)\end{array}$} & \multicolumn{2}{|c|}{$\begin{array}{c}\text { Minimum DO } \\
\text { Concentration } \\
(\mathrm{mg} / \mathrm{L})\end{array}$} & \multicolumn{2}{|c|}{$\begin{array}{c}\text { DO Standard } \\
(\mathbf{m g} / \mathrm{L})\end{array}$} \\
\hline & $\begin{array}{l}\mathrm{MM} \\
(2)\end{array}$ & $\begin{array}{l}\mathrm{MB} \\
(3) \\
\end{array}$ & & $\begin{array}{l}\mathrm{MM} \\
\mathbf{( 5 )}\end{array}$ & $\begin{array}{l}\mathrm{MB} \\
(6)\end{array}$ & $\begin{array}{c}\text { Desirable } \\
(\mathbf{7})\end{array}$ & $\begin{array}{c}\text { Permissible } \\
\text { (8) }\end{array}$ \\
\hline$D_{1}$ & 0.64 & 0.30 & $r_{1}$ & 9.89 & 9.12 & 10.110 & 6.60 \\
\hline$D_{2}$ & 0.70 & 0.35 & $r_{2}$ & 8.76 & 7.83 & 9.355 & 6.85 \\
\hline$D_{3}$ & 0.72 & 0.47 & $r_{3}$ & 8.50 & 7.12 & 9.664 & 6.14 \\
\hline$D_{4}$ & 0.66 & 0.35 & $r_{4}$ & 8.80 & 7.95 & 9.278 & 6.28 \\
\hline$D_{5}$ & 0.70 & 0.36 & $r_{3}$ & 9.17 & 8.12 & 10.2200 & 7.20 \\
\hline$D_{6}$ & 0.75 & 0.90 & $r_{0}$ & 7.65 & 6.90 & 9.40 & 6.90 \\
\hline$D_{7}$ & 0.77 & 0.90 & $r_{7}$ & 6.90 & 6.25 & 8.85 & 5.85 \\
\hline$D_{8}$ & 0.74 & 0.69 & $r_{8}$ & 6.6 & 6.15 & 8.15 & 6.15 \\
\hline$D_{9}$ & 0.49 & 0.30 & $r_{9}$ & 6.07 & 5.50 & 8.00 & 5.50 \\
\hline
\end{tabular}

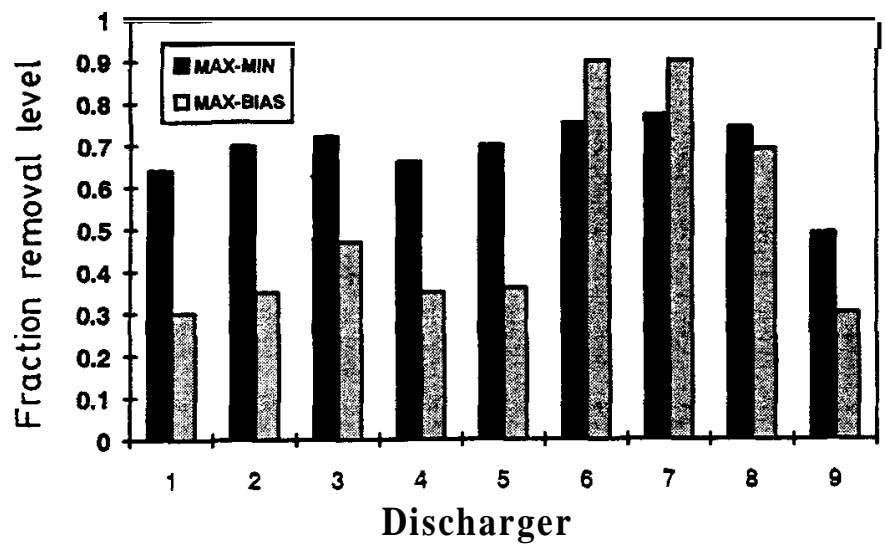

FIG. 9. Bar Chart of Fraction Removal Levels

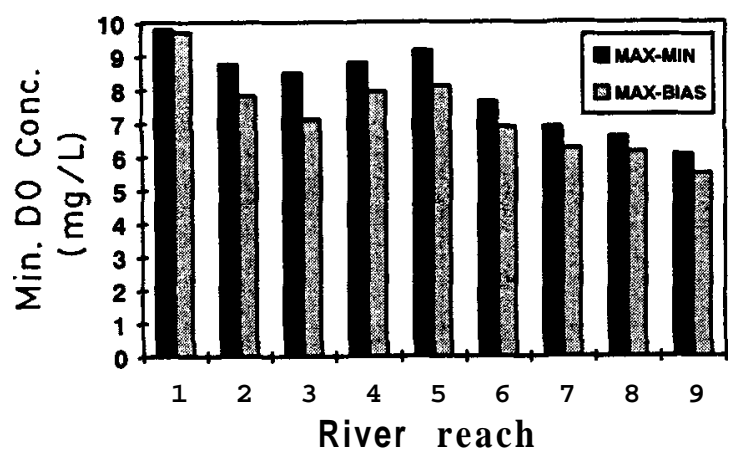

FIG. 10. Bar Chart of Minimum DO Concentrations pollution control agency. On the other hand, the MAX-BIAS formulation favors the dischargers in general by suggesting lower fraction removal levels. The DO concentration in the river reaches 6,8 , and 9 are at the minimum permissible levels showing critical water quality conditions in these reaches.

The optimal value of the minimum satisfaction level, $A$, in the system are 0.2283 and 0.0 for the MAX-MIN and MAXBIAS formulations, respectively. Similarly, the optimal values of the bias index, $\eta$, are -11.5073 and -2.0888 for the MAXMIN and MAX-BIAS formulations, respectively. The upper and lower bounds of A reflect two extreme scenarios in the system. The upper bound, $A=1$, indicates that all the goals have been completely satisfied and therefore represents a noconflict scenario. The lower bound, $\mathrm{A}=0$, indicates that at least one goal has a zero satisfaction level and therefore represents a conflict scenario. Any intermediate value of A represents the degree of conflict that exists in the system. The MAX-MIN formulation aims at achieving a fair-compromise solution by reducing the degree of conflict in the system. It may be expected for a water quality management problem that the value of the minimum satisfaction level, A, will be closer to zero than to unity as with the example illustrated. This indicates that a conflict scenario cannot be avoided in the system. The existence of a conflict scenario in water quality management problems is due to the compound effect of the conflicting objectives of the pollution control agency and the dischargers, and the relatively low assimilative capacity of the river network. The smaller value of the bias index, $\eta$, for MAX-MIN formulation may be related to the improved water quality indicated by the higher values of minimum DO concentration. The higher value of the bias index, $\eta$, for the MAX-BIAS formulation indicates a solution that favors the dischargers.

\section{CONCLUSION}

The fuzzy waste load allocation model, FWLAM, provides a new paradigm for water quality management of a river system. The MAX-MIN and MAX-BIAS formulations provide decision-making tools that facilitate more realistic cooperation between the pollution control agency and dischargers, and between the dischargers themselves. FWLAM is an easily implementable decision-making tool in water quality management of a river system. The model is capable of incorporating the conflicting objectives of the pollution control agency and dischargers in the system. The vagueness associated with setting up the water quality criteria, and the aspirations of the pollution control agency and dischargers can be effectively quantified using appropriate membership functions for the various fuzzy goals. A salient feature of the model is the elimination of waste treatment cost curves. The MAX-MIN formulation of FWLAM favors the pollution control agency by enhancing the water quality of the river system. The MAXBIAS formulation favors the dischargers by suggesting lower fraction removal levels. FWLAM provides flexibility for the pollution control agency and dischargers to specify their aspirations independently and thus avoids the difficulty of assigning unknown relative weights. The cooperation between the pollution control agency and dischargers, and the dischargers among themselves can be made more realistic and scientific using FWLAM as a decision-making tool for water quality management of a river system. FWLAM does not limit its application to any particular pollutant or water quality parameter in the river system. Given appropriate transfer functions for the spatial and temporal distribution of the pollutants in a water body, FWLAM can be used for water quality management of the water body. In a general sense, FWLAM is adaptable to various environmental systems where a sustainableand efficient use of environment is of interest. 


\section{ACKNOWLEDGMENT}

The writers sincerely thank the anonymous reviewers for their comments and suggestions to improve the quality of the paper.

\section{APPENDIX 1. REFERENCES}

Arbabi, M., and Elzinga. J. (1975). "A general linear approach to stream water quality modeling." Water Resour: Res., 11(2), 191-196.

Bellman, R. E., and Zadeh. L. A. (1970). "Decision-making in a fuzzy environment." Mgmt. Sci., 17(4), B141-B164.

Burn, D. H., and McBean, E. A. (1985). "Optimization modeling of water quality in an uncertain environment." Water Resour: Res., 21(7), $934-$ 940.

Bum, D. H.. and McBean, E. A. (1986). "Linear stochastic optimization applied to bio-chemical oxygen demand: Dissolved Oxygen Modelling." Can. J. Civ. Engrg., 13, 249-254.

Cardwell. H., and Ellis. H. (1993). "Stochastic dynamic programming models for water quality management." Water Resour: Res., 29(4), 803-813.

Cohon, J. L. (1978). Multiobjective programming and planning. Academic Press, Inc.. New York, N.Y., 247-249.

Dubois, D., and Prade, H. (1980). Fuzzy sets und systems: Theory and applications. Academic Press, Inc., New York, N.Y., 9-35.

Ellis, J. H. (1987). "Stochastic water quality optimization using imbedded chance constraints." Water Resour: Res., 23(12), 2227-2238.

Feng, Y. (1983). "A method using fuzzy mathematics to solve the vector maximum problem." Fuzzy Sets and Systems, 9, 129-136.

Fugiwara, O., Gnanendran, S. K., and Ohgaki, S. (1986). "River quality management under stochastic streamflow." J. Envir: Engrg.. ASCE, $112(2), 185-198$.

Fugiwara, O., Gnanendran, S. K., and Ohgaki, S. (1987). "Chance constrained model for water quality management." J. Envir: Engrg.. ASCE, 113(5), 1018-1031.

Fugiwara, O., Puangmaha, W., and Hanaki, K. (1988). "River basin water quality management in stochastic environment." J. Envir: Engrg., ASCE, 114(4), 864-877.

Gromiec, M. J., Loucks, D. P., and Orlob, G. T. (1983). "Stream quality modeling." Mathematical modeling for water quality: Streams, lakes and reservoirs, G. T. Orlob. ed., John Wiley \& Sons, Inc.. New York, N.Y., 176-226.

James, A., and Elliot, D. T. (1993). "Models of water quality in rivers." An introduction to water quality modeling, (2nd Ed.), A. James, ed., John Wiley \& Sons, Inc., New York, N.Y., 141- 181.

Kaufmann. A. (1975). Introduction to the theory of fuzzy sets. Vol. I:

Fundamental theoretical elements. Academic Press, Inc., New York. N.Y.. $1-40$.

Kindler, J. (1992). "Rationalizing water requirements with aid of fuzzy allocation model." J. Water Resour: Plng. and Mgmt., ASCE, 118(3), 308-323.

Klir, G. J., and Folger, T. A. (1988). Fuzzy sets, uncertainty and infor. mation. Prentice Hall, lnc.. Englewood Cliffs, N.J.. 1-64.

Klir, G. J., and Yuan, B. (1995). Fuzzy sets and fuzzy logic: Theory and applications. Prentice Hall, Inc.. Englewood Cliffs, N.J., 1-96, 390417.

Lohani, B. N., and Thanh, N. C. (1978). "Stochastic programming model for water quality management in a river.' J. WPCF, 50, 2175-2182.

Lohani. B. N., and Thanh, N. C. (1979). "Probabilistic water quality control policies." J. Envir: Engrg., ASCE, 105(4), 713-725.

Loucks, D. P. (1983). "Models for management applications." Mathematical modeling for water quality: Streams, lakes and reservoirs, $G$. T. Orlob, ed. ,John Wiley \& Sons, Inc., New York, N.Y., 468-509.

Loucks, D. P., Stedinger. J. R., and Haith, D. A. (1981). Water resource systems planning and analysis. Prentice Hall. Inc., Englewood Cliffs, N.J., $427-545$.

Rao, S. S. (1993). "Optimization using fuzzy set theory." Structural optimization: Status and promise. M. P. Kamat, ed., Am. Inst, of Aeronautics and Astronautics, 637-661.

Sakawa, M. (1995). "Fuzzy programming." Fuzzy systems for management, K. Asai, ed., IOS Press, Inc.. Bruke, 57-78.

Thomann. R. V. (1972). Systems analysis for water quality management. McGraw-Hill Inc., New York, N.Y.,204-252.

Thomann. R. V., and Mueller, J. A. (1987). Principles of water quality modeling and control. Harper and Row Publishers, New York, N.Y., $1-89,261-384$

Zadeh, L. A. (1965). "Fuzzy sets." Information and Control, 8, 338353 .

Zimmermann, H. J. (1978). "Fuzzy programming and linear programming with several objective functions." Fuzzy Sets and Systems, 1, 45-55.
Zimmermann, H. J. (1985). "Application of fuzzy set theory to mathematical programming." Informarion Sci, 36, 29-58.

\section{APPENDIX II. NOTATION}

Thefollowing symbols are used in this paper:

$A, A_{k}, \mathrm{~B}=$ fuzzy sets;

$C=$ fuzzy constraint;

$\mathrm{C}_{\#}=$ concentration of water quality parameter $i$ at meshpoint I;

$C_{u l}^{D}, C_{u}^{L}=$ desirable and permissible levels for $C_{u}$;

$C_{m}=$ concentration of water quality parameterj at meshpoint $\boldsymbol{l}$;

$C_{\mu}^{D}, C_{\mu}^{H}=$ desirable and permissible levels for $C_{\mu}$;

$C_{w l}=$ concentration of water quality parameter $w$ at meshpoint $\mathbf{I}$

$C_{l}=$ DO deficit at meshpoint 1 ;

$C_{1}^{D}, C_{1}^{H}=$ desirable and permissible DO deficits at meshpoint 1 ;

$d_{i l}, d_{i m n}, d_{f l}, d_{j m n}=$ deviations of satisfaction levels from minimum satisfaction level $\lambda$;

$d_{1}, d_{2}, d_{3}, d_{4}=$ summed deviations of satisfaction levels from minimum satisfaction level A

$D=$ set of dischargers;

$D_{m}=$ dischargerm;

$E_{l l}, E_{j l}=$ fuzzy goals of pollution control agency with regard to $C_{l l}$ and $C_{\mu l}$, respectively;

$f_{w / m n}(\cdot, \cdot), f_{w l p n}(\cdot)=$ transfer functions;

$F, F_{y}=$ fuzzy goals;

$F_{i m n}, F_{\text {jmn }}=$ fuzzy goals of discharger $\mathrm{m}$ with regard to $x_{i m n}$ and $x_{j m n}$, respectively;

$g_{h}(X)=$ crisp constraint $\boldsymbol{h}$;

$G=$ crisp set;

$L_{w l m n}=$ concentration of pollutant $n$ prior to treatment from discharger $m$ that affects water quality parameter $\boldsymbol{w}$ at meshpoint 1 ;

$L_{w i p n}=$ concentration of pollutant $\boldsymbol{n}$ from uncontrollable source $p$ that affects water quality parameter $\boldsymbol{w}$ at meshpoint $\mathrm{I}$;

$n_{\boldsymbol{A}}=$ total number of fuzzy sets $\boldsymbol{A}_{\boldsymbol{k}}$;

$n_{F}=$ total number of fuzzy goals $F_{y}$;

$n_{G}=$ total number of crisp constraints $g_{n}$;

$N_{d}=$ total number of dischargers;

$N_{\rho}=$ total number of pollutants;

$N_{q}=$ total number of water quality meshpoints;

$N_{s}=$ total number of water quality parameters that belong to set $S$;

$N_{t}=$ total number of uncontrollable sources of pollutants;

$N_{v}=$ total number of water quality parameters that belong to set $V$;

$P=$ set of pollutants;

$Q=$ set of water quality meshpoints;

$r_{\boldsymbol{e}}=$ river reach $\boldsymbol{e}$;

$S=$ set of water quality parameters for which desirable levels is less than permissible level;

$T=$ set of uncontrollable sources of pollutants;

$U=$ universal set;

$V=$ set of water quality parameters for which desirable level is less than permissible level;

$x=$ element in set $U$;

$x_{i m n}, x_{j m n}=$ fraction removal levels of the pollutant $n$ from discharger $\boldsymbol{m}$ to control water quality parameters $i$ and $j$, respectively;

$x_{l m n}^{L}, x_{j m n}^{L}=$ minimum fraction removal levels set by discharger m;

$\boldsymbol{x}_{i m n}^{M}, x_{j m s}^{M}=$ maximum fraction removal levels set by discharger $\boldsymbol{m}$;

$x_{i m n}^{\mathrm{MTN}}, x_{j m n}^{\mathrm{MTN}}=$ minimum fraction removal levels imposed by pollution control agency;

$x_{i m n}^{\mathrm{MAX}}, \boldsymbol{x}_{j m n}^{\mathrm{MAX}}=$ technologically possible maximum fraction removal levels; 
$x_{i m n}^{*}, x_{j m n}^{*}=$ optimal fraction removal levels;

$x_{m}=$ fraction removal level of BOD point-source for discharger $\boldsymbol{m}$;

$\boldsymbol{x}_{\boldsymbol{m}}^{\mathbf{L}}, \mathbf{x}_{, \boldsymbol{M}^{\prime}}=$ minimum and maximum fraction removal level of BOD set by discharger $m$;

$\boldsymbol{x}_{m}^{\mathrm{MIN}}=$ minimum fraction removal level of BOD imposed by pollution control agency on discharger $m$;

$x^{*}=$ optimal solution for fuzzy decision $Z$;

$\boldsymbol{X}=$ space of alternatives;

$\hat{\mathbf{X}}=$ vector of fraction removal levels;

$\hat{X}^{*}=$ vector of optimal fraction removal levels;

$X^{*}=$ optimal solution of fuzzy decision $Z$ corresponding to $\mathrm{X}$,

$Z$ = fuzzy decision;

$\alpha_{(\cdot,)}, \beta_{(\cdots,)}=$ exponents in membership functions of fuzzy goals; $\eta=$ bias index

$\mathrm{A}=$ minimum satisfaction level; and

$\lambda^{*}=$ maximized minimum (max-min) satisfaction level.

\section{Subscripts}

e $=$ subscript for river reach;

$\mathrm{h}=$ subscript for crisp constraint $g$;

i, $j=$ water quality parameters that belong to sets $\mathrm{V}$ and $\mathcal{S}$, respectively;

$k=$ subscript for fuzzy set A;

$l=$ water quality meshpoint;

$\mathrm{m}=$ discharger;

$n=$ pollutant;

$p=$ uncontrollable source of pollutant; and

$\mathrm{y}=$ subscript for fuzzy goal $\mathbf{F}$. 